\title{
Study on Synthesis, Characterization, Thermal Stability and Conductivity Properties of a New Conjugated Oligoazomethine and some of its Metal Complexes
}

\author{
İsmet Kaya $\cdot$ Ali Bilici $\cdot$ Mehmet Saçak
}

Received: 13 February 2009/ Accepted: 25 May 2009/Published online: 6 June 2009

(c) The Author(s) 2009. This article is published with open access at Springerlink.com

\begin{abstract}
A novel azomethine oligomer of 2,3-bis[(2hydroxyphenyl)methylene]diaminopyridine (HPMDAP) was first synthesized by oxidative polycondensation reaction using air and $\mathrm{NaOCl}$ as oxidative agents. Optimum reaction conditions for the oxidative polycondensation and the main parameters of the process were established. At optimum reaction conditions, the yield of the product was found to be $69 \%$. Oligomeric complexes of 2,3-bis[(2-hydroxyphenyl)methylene]diaminopyridine with $\mathrm{Cd}(\mathrm{II}), \mathrm{Co}(\mathrm{II}), \mathrm{Cu}(\mathrm{II}), \mathrm{Ni}(\mathrm{II}), \mathrm{Fe}(\mathrm{II}), \mathrm{Pb}(\mathrm{II}), \mathrm{Cr}$ (III) and $\mathrm{Zn}(\mathrm{II})$ were successfully prepared. Structures of monomer, oligomer and some oligomer metal complexes obtained were confirmed by FT-IR, UV-vis, ${ }^{1} \mathrm{H}$ - and ${ }^{13} \mathrm{C}-\mathrm{NMR}$ and elemental analysis. Characterization was carried out by TG-DTA, size exclusion chromatography (SEC), magnetic moment and solubility tests. The ${ }^{1} \mathrm{H}$ - and ${ }^{13} \mathrm{C}-\mathrm{NMR}$ data showed that polymerization proceed by $\mathrm{C}-\mathrm{C}$ coupling of ortho and para positions according to $-\mathrm{OH}$ group of HPMDAP. Elemental analysis of chelates suggests that the metal ligand ratio is about 1:2. Molecular weight distribution values of the products were determined by size exclusion chromatography (SEC). According to TG analyses, the carbonaceous residues of HPMDAP and OHPMDAP were found to be 34.94 and $29.36 \%$ at $1000{ }^{\circ} \mathrm{C}$, respectively. Thermal analyses of Cd,
\end{abstract}

İ. Kaya $(\bowtie) \cdot$ A. Bilici · M. Saçak

Department of Chemistry, Çanakkale Onsekiz Mart University,

Çanakkale 17020, Turkey

e-mail: kayaismet@hotmail.com

I. Kaya $\cdot$ A. Bilici · M. Saçak

Faculty of Science, Department of Chemistry, Ankara

University, Tandoğan, Ankara, Turkey
$\mathrm{Co}, \mathrm{Cu}, \mathrm{Ni}, \mathrm{Fe}, \mathrm{Pb}, \mathrm{Cr}$ and $\mathrm{Zn}$ oligomer-metal complexes were also investigated under $\mathrm{N}_{2}$ atmosphere between 15 and $1000{ }^{\circ} \mathrm{C}$. Electrical conductivities of OHPMDAP and its metal complexes were also measured with four probe technique.

Keywords Oligoazomethine - Oxidative polycondensation · Oligo-2,3-bis[(2-hydroxyphenyl) methylene]diaminopyridine $\cdot$ Oligomer-metal complexes . Thermal degradation - Electrical conductivity

\section{Introduction}

Polymers of phenols and aromatic amine compounds have found wide application in a number of areas such as coatings, laminates and photoresists [1,2]. Besides possessing good thermal properties, these polymers or oligomers can be doped to make them electrically conductive [3]. The molecular weight distributions of polyphenols significantly influence functional properties [4]. A large number of polymeric Schiff base complexes with a variety of central metal ions and ligand systems have been synthesized [5]. These compounds have emerged as a new generation materials with tremendous potentials in fields like superconducting materials, heat stability materials from Schiff bases of salicylaldehyde derivatives [6-10]. The structures of some polymer-metal ion complexes have been reported in the literature [11-13]. They also have useful properties such as paramagnetizm, electrochemical cell and resistance to high energy [14-18]. New oxo-vanadium(IV) Schiff base complexes derived from amino acids and aromatic $o$-hydroxyaldehydes were studied by Pessoa et al. [19]. Conductivity properties of $\mathrm{Cu}$ (II), $\mathrm{Co}$ (II) and $\mathrm{Ni}$ (II) complex compounds of 
oligo-2-[(4-chlorophenyl) imino methylene] phenol were studied by Kaya et al. [20]. Antimicrobial properties of oligophenols with a Schiff base substitute and their oligomer metal complex compounds were investigated by Kaya et al. [21]. $\mathrm{Cu}(\mathrm{II}), \mathrm{Zn}$ (II) and $\mathrm{Co}(\mathrm{II})$ complexes of oligosalicylaldehyde had been synthesized and their thermal properties had been investigated by Mart et al. [22]. Additional functions for oligophenols may be the cleaning of poisonous heavy metals in the industrial waste waters. In addition, Schiff base compounds had been used for the determination of transition metals in some natural food samples [23]. Therefore, the synthesis of oligomers and oligomer-metal complexes are very important in analytical, environmental and food chemistry.

In this study, we investigated the effects of different parameters such as temperature, time and initial concentration of $\mathrm{NaOCl}$, for oligo-2,3-bis[(2-hydroxyphenyl) methylene]diaminopyridine in alkaline medium. The HPMDAP and OHPMDAP were characterized by using FTIR, UV-vis, ${ }^{1} \mathrm{H}_{-}{ }^{13} \mathrm{C}-\mathrm{NMR}$, elemental analysis, TG-DTA, magnetic moment and SEC techniques. OHPMDAP-Cd, OHPMDAP-Co, OHPMDAP-Cu, OHPMDAP-Cr, OHPMDAP-Fe, OHPMDAP-Ni, OHPMDAP-Pb and OHPMDAP-Zn, were characterized by using FT-IR, elemental analysis, magnetic moment and TG-DTA techniques. Electrical properties of doped and undoped polymer were determined with four-point probe technique at room temperature and atmospheric pressure by using Keithley 2400 conductivity instrument.

\section{Materials and Methods}

\subsection{Materials}

Salicylaldehyde, 2,3-diaminopyridine, methanol, ethanol, benzene, toluene, ethyl acetate, $\mathrm{CH}_{2} \mathrm{Cl}_{2}, \mathrm{CHCl}_{3}, \mathrm{CCl}_{4}$, acetone, hexane, THF, DMF, DMSO, $\mathrm{H}_{2} \mathrm{SO}_{4}(98 \%), \mathrm{KOH}$, hydrochloric acid $(\mathrm{HCl}, 37 \%) \mathrm{Co}(\mathrm{AcO})_{2} 4 \mathrm{H}_{2} \mathrm{O}, \mathrm{Ni}(\mathrm{AcO})_{2}$ $4 \mathrm{H}_{2} \mathrm{O}, \mathrm{Cu}(\mathrm{AcO})_{2} 4 \mathrm{H}_{2} \mathrm{O}, \mathrm{FeSO}_{4} 7 \mathrm{H}_{2} \mathrm{O}, \mathrm{Zn}(\mathrm{AcO})_{2} 4 \mathrm{H}_{2} \mathrm{O}$, $\mathrm{Pb}(\mathrm{AcO})_{2} \quad 3 \mathrm{H}_{2} \mathrm{O}, \mathrm{CrCl}_{3} \quad 6 \mathrm{H}_{2} \mathrm{O}$ and $\mathrm{Cd}(\mathrm{AcO})_{2} \quad 2 \mathrm{H}_{2} \mathrm{O}$ were supplied from Merck Chem. Co. (Germany) and they were used as received. Sodium hypochlorite $(\mathrm{NaOCl}),(5 \%$ aqueous solution) was supplied from Paksoy Chem. Co. (Turkey).

\subsection{Preparation of HPMDAP}

2,3-bis[(2-hydroxyphenyl)methylene]diaminopyridine was prepared by the condensation of salicylaldehyde (1.22 g, $0.01 \mathrm{~mol})$ and 2,3-diaminopyridine $(0.55 \mathrm{~g}, 0.005 \mathrm{~mol})$ in $15 \mathrm{~mL}$ of methanol, by boiling the mixture under reflux for $3 \mathrm{~h}$ (Scheme 1). The precipitated 2,3-bis[(2-hydroxyphenyl)methylene]diaminopyridine was filtered and recrystallized from methanol and dried in a vacuum desiccator (yield, 78\%).

${ }^{1} \mathrm{H}-\mathrm{NMR}$ (DMSO): $\delta \mathrm{ppm}, 9.57(\mathrm{~s}, 1 \mathrm{H},-\mathrm{CH}=\mathrm{N}-), 8.99$ (s, 1H, $-\mathrm{CH}=\mathrm{N}-), 13.17(\mathrm{~s}, 1 \mathrm{H},-\mathrm{OH}), 12.64(\mathrm{~s}, 1 \mathrm{H},-\mathrm{OH})$, 7.05 (d, 2H, Ar-Ha), 7.50 (t, 2H, Ar-Hb), 6.99 (t, 2H, ArHc), 7.93 (d, 1H, Ar-Hd), 7.82 (d, 1H, Ar-Hi), 8.46 (d, 1H,<smiles>Nc1cccnc1N</smiles><smiles></smiles><smiles>[Y]c1cc([X])c(O)c(/C=N/c2ncccc2/N=C/c2cc([N+](=O)[O-])cc(I)c2O)c1</smiles>

Scheme 1 Synthesis of monomer and oligomer 
$\mathrm{Ar}-\mathrm{He}), 7.46$ (t, 1H, Ar-Hf), $7.72(\mathrm{~d}, 1 \mathrm{H}, \mathrm{Ar}-\mathrm{Hg})$. ${ }^{13} \mathrm{C}-\mathrm{NMR}$ (DMSO): $\delta$ ppm, 161.63 (C1-ipso), 117.04 (C2), 133.70 (C3), 119.05 (C4), 134.35 (C5), 120.05 (C6-ipso), 166.06 (C7), 139.57 (C8-ipso), 147.11 (C9), 124.49 (C10), 129.51 (C11), 151.04 (C12-ipso), 164.67 (C13), 119.77 (C14-ipso), 132.76 (C15), 119.72 (C16), 134.75 (C17), 117.24 (C18), 160.79 (C19).

\subsection{Synthesis of OHPMDAP with $\mathrm{NaOCl}$ and Air Oxidants in Aqueous Alkaline Medium}

OHPMDAP was synthesized by oxidative polycondensation reaction of HPMDAP with aqueous solution of $\mathrm{NaOCl}$ $(5 \%)$ and air, respectively, as follows (Scheme 1) [24]. The reaction mixtures were stirred at the various temperatures and durations, and the conditions used are given in Table 1.

${ }^{1} \mathrm{H}-\mathrm{NMR}\left(\mathrm{DMSO}-\mathrm{d}_{6}\right): \delta \mathrm{ppm}, 9.56(\mathrm{~s}, 1 \mathrm{H},-\mathrm{CH}=\mathrm{N}-)$, $8.98(\mathrm{~s}, 1 \mathrm{H},-\mathrm{CH}=\mathrm{N}-), 13.18(\mathrm{~s}, 1 \mathrm{H},-\mathrm{OH}), 12.60(\mathrm{~s}, 1 \mathrm{H}$, $-\mathrm{OH}), 7.02$ (d, 2H, Ar-Ha), 7.48 (t, 2H, Ar-Hb), 6.97 (t, 2H, $\mathrm{Ar}-\mathrm{Hc}), 7.91$ (d, 1H, Ar-Hd), 7.80 (d, 1H, Ar-Hi), 8.45 (d, $1 \mathrm{H}, \mathrm{Ar}-\mathrm{He}), 7.45$ (t, 1H, Ar-Hf), $7.71(\mathrm{~d}, 1 \mathrm{H}, \mathrm{Ar}-\mathrm{Hg}) .{ }^{13} \mathrm{C}-$ NMR (DMSO): $\delta$ ppm, 161.64 (C1-ipso), 117.84 (C2, 18), 133.69 (C3), 119.95 (C4, 16), 134.33 (C5), 120.04 (C6-ipso), 166.01 (C7), 139.55 (C8-ipso), 147.09 (C9), 124.46 (C10),
129.47 (C11), 151.03 (C12-ipso), 164.65 (C13), 119.73 (C14-ipso), 132.75 (C15), 134.73 (C17), 160.80 (C19), 143.05 (new peak of $C-C$ coupling system).

\subsection{Synthesis of OHPMDAP-Metal Complexes}

A solution of $\mathrm{Co}(\mathrm{AcO})_{2} 4 \mathrm{H}_{2} \mathrm{O}, \mathrm{Ni}(\mathrm{AcO})_{2} 4 \mathrm{H}_{2} \mathrm{O}, \mathrm{Cu}(\mathrm{AcO})_{2}$ $\mathrm{H}_{2} \mathrm{O}, \mathrm{FeSO}_{4} \quad 7 \mathrm{H}_{2} \mathrm{O}, \mathrm{Zn}(\mathrm{AcO})_{2} 2 \mathrm{H}_{2} \mathrm{O}, \mathrm{Pb}(\mathrm{AcO})_{2} \quad 3 \mathrm{H}_{2} \mathrm{O}$, $\mathrm{CrCl}_{3} \quad 6 \mathrm{H}_{2} \mathrm{O}$ or $\mathrm{Cd}(\mathrm{AcO})_{2} \quad 2 \mathrm{H}_{2} \mathrm{O}(2 \mathrm{mmol})$ in methanol $(\mathrm{MeOH})(10 \mathrm{~mL})$ was added to a solution of OHPMDAP ( $2 \mathrm{mmol} / \mathrm{unit}$, Table 1 , sample no.:3) in THF $(20 \mathrm{~mL})$. The mixture was stirred for $3 \mathrm{~h}$ at room temperature (Scheme 2). The precipitated complex was filtered, washed with cold $\mathrm{MeOH} / \mathrm{THF}$ (1:1) and then dried in vacuum oven.

\subsection{Electrical Properties}

Conductivity was measured with a Keithley 2400 Electrometer (Keithley, Ohio, USA). The pellets were pressed with hydraulic press under pressure of $1687.2 \mathrm{~kg} / \mathrm{cm}^{2}$. Iodine doping was carried out by exposure of the pellets to iodine vapor at atmospheric pressure and room temperature in a desiccator [25].
Table 1 Oxidative polycondensation reaction parameters of oligo-2,3-bis [(2-hydroxyphenyl) methylene]diaminopyridine with $\mathrm{NaOCl}$ (sample no.: 1-14) and air (sample no.: 15-24) in aqueous $\mathrm{KOH}$
The initial concentration of HPMDAP was $0.05 \mathrm{~mol} \mathrm{~L}^{-1}$

\begin{tabular}{|c|c|c|c|c|c|}
\hline Sample no. & $\begin{array}{l}{[\mathrm{KOH}]_{\mathrm{o}}} \\
\left(\mathrm{mol} \mathrm{L}^{-1}\right)\end{array}$ & $\begin{array}{l}{[\mathrm{NaOCl}]_{\mathrm{o}}} \\
\left(\mathrm{mol} \mathrm{L}^{-1}\right) / \mathrm{Air}(\mathrm{L} / \mathrm{h})\end{array}$ & Temp. $\left({ }^{\circ} \mathrm{C}\right)$ & Time (h) & $\begin{array}{l}\text { Yield of } \\
\text { OHPMDAP (\%) }\end{array}$ \\
\hline 1 & 0.05 & 0.05 & 30 & 1 & 62 \\
\hline 2 & 0.05 & 0.05 & 40 & 1 & 66 \\
\hline 3 & 0.05 & 0.05 & 50 & 1 & 69 \\
\hline 4 & 0.05 & 0.05 & 60 & 1 & 64 \\
\hline 5 & 0.05 & 0.05 & 70 & 1 & 52 \\
\hline 6 & 0.05 & 0.05 & 50 & 3 & 53 \\
\hline 7 & 0.05 & 0.05 & 50 & 5 & 42 \\
\hline 8 & 0.05 & 0.05 & 50 & 20 & 25 \\
\hline 9 & 0.1 & 0.05 & 40 & 1 & 27 \\
\hline 10 & 0.1 & 0.05 & 50 & 1 & 30 \\
\hline 11 & 0.1 & 0.05 & 60 & 1 & 36 \\
\hline 12 & 0.1 & 0.05 & 70 & 1 & 30 \\
\hline 13 & 0.1 & 0.05 & 80 & 1 & 22 \\
\hline 14 & 0.05 & 0.1 & 60 & 1 & 44 \\
\hline 15 & 0.05 & 8.5 & 30 & 1 & 41 \\
\hline 16 & 0.05 & 8.5 & 50 & 1 & 50 \\
\hline 17 & 0.05 & 8.5 & 60 & 1 & 55 \\
\hline 18 & 0.05 & 8.5 & 70 & 1 & 47 \\
\hline 19 & 0.05 & 8.5 & 80 & 1 & 34 \\
\hline 20 & 0.05 & 8.5 & 90 & 1 & 29 \\
\hline 21 & 0.05 & 8.5 & 60 & 0.5 & 39 \\
\hline 22 & 0.05 & 8.5 & 60 & 3 & 47 \\
\hline 23 & 0.05 & 8.5 & 60 & 10 & 43 \\
\hline 24 & 0.05 & 8.5 & 60 & 15 & 32 \\
\hline
\end{tabular}


Scheme 2 Synthesis of oligomer-metal complexes<smiles>[Y]c1cc([X])c(O)c(/C=N\c2ncccc2/N=C/c2cc([X])[14c]([Y4])c(C)c2O)c1</smiles>

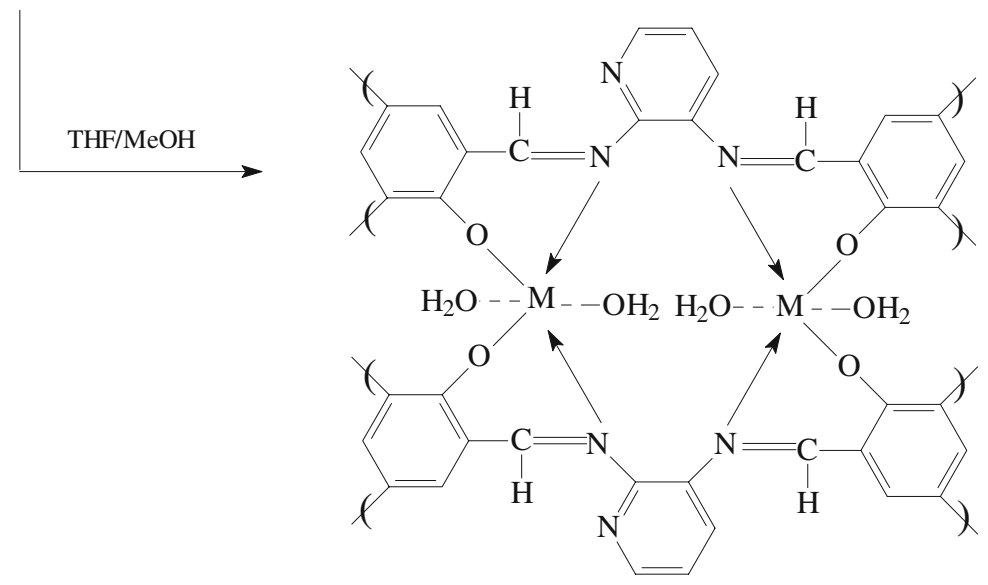

\subsection{Optical Properties}

The optical band gaps $\left(E_{g}\right)$ of monomer, oligomer and oligomer-metal complexes were calculated from their absorption edges. Ultraviolet-visible (UV-vis) spectra of compounds were measured with Perkin Elmer Lambda 25 (Massachusetts, USA) by using methanol and DMSO as solvents. The absorption spectra of monomer, oligomer and oligomer-metal complexes were recorded by using $\mathrm{MeOH}$ and DMSO, respectively, at $25^{\circ} \mathrm{C}$.

\subsection{Characterization Techniques}

The infrared spectra were measured by Perkin Elmer Spectrum One FT-IR system. The FT-IR spectra were recorded using universal ATR sampling accessory within the wavelengths of $4000-550 \mathrm{~cm}^{-1}$. Elemental analyses were carried out with a Carlo Erba 1108 analyser. HPMDAP and OHPMDAP were characterized by using ${ }^{1} \mathrm{H}$ and ${ }^{13} \mathrm{C}$-NMR spectra (Bruker AC FT-NMR spectrometer operating at 400 and $100.6 \mathrm{MHz}$, respectively) and recorded by using deuterated DMSO- $\mathrm{d}_{6}$ as a solvent at $25^{\circ} \mathrm{C}$. The tetramethylsilane was used as internal standard. Thermal data were obtained by using Perkin Elmer Diamond Thermal Analysis. The TG-DTA measurements were made between 15 and $1000{ }^{\circ} \mathrm{C}$ (under $\mathrm{N}_{2}$ with a rate of $\left.10^{\circ} \mathrm{C} / \mathrm{min}\right)$. The number-average molecular weight $\left(M_{n}\right)$, weight-average molecular weight $\left(M_{w}\right)$ and polydispersity index (PDI) were determined by SEC (Shimadzu Co. Japan) with a Macherey-Nagel GmbH \& Co. (Germany) $7.7 \mathrm{~mm}$ i.d. $\times 300 \mathrm{~mm}$ columns $(100 \AA$ and $7 \mathrm{~nm}$ diameter loading material), by using $\mathrm{DMF} / \mathrm{MeOH}$ eluent (v/v, 4/
1, $0.4 \mathrm{~mL} \mathrm{~min}^{-1}$ ), polystyrene standards and a refractive index detector. The magnetic moments of oligomer-metal complexes were measured by a MK-1 model Gouy Balance (Christison Scientific Equipment Ltd.) at room temperature. Metal analyses of oligomer-metal complexes were carried out by AAS Shimadzu 6200 (Japan) in solution prepared by decomposition of the complexes with $\mathrm{HNO}_{3}$ followed by dilution with deionized water.

\section{Results and Discussion}

\subsection{Synthesis and Solubility of Compounds}

The alkaline solution of 2,3-bis[(2-hydroxyphenyl)methylene]diaminopyridine was interacted by oxidants (air and $\mathrm{NaOCl}$ ) and oligomers precipitated immediately with brown colour at the reaction medium. The oxidative polycondensation reaction conditions of HPMDAP with $5 \% \mathrm{NaOCl}$ solution in aqueous alkaline medium are given in Table 1. The yield of OHPMDAP solution was $62 \%$ for $\mathrm{NaOCl}$ oxidant for $1 \mathrm{~h}$ at $30^{\circ} \mathrm{C}$. As can be seen from Table 1, the amount of products first increased with increasing temperature but than decreased. When molar amount of $\mathrm{NaOCl}$ increased in two folds, total yield decreased from $64 \%$ to $44 \%$ (see Table 1, Sample No. 4 and 23) under same conditions. The yield of OHPMDAP was $69 \%$ at optimum conditions of $[\mathrm{HPMDAP}]_{0}=$ $[\mathrm{KOH}]_{0}=[\mathrm{NaOCl}]_{0}=0.05 \mathrm{~mol} / \mathrm{L}$, at $50{ }^{\circ} \mathrm{C}$ for $1 \mathrm{~h}$. The yield of OHPMDAP was $25 \%$ under the other reaction conditions of $[\mathrm{HPMDAP}]_{0}=[\mathrm{KOH}]_{0}=[\mathrm{NaOCl}]_{0}=$ $0.05 \mathrm{~mol} / \mathrm{L}$ at $50{ }^{\circ} \mathrm{C}$ for $20 \mathrm{~h}$. 
The oxidative polycondensation reaction conditions of HPMDAP with air in aqueous alkaline medium are given in Table 1. At the oxidative polycondensation reaction of HPMDAP, when air was passed at a rate of $8.5 \mathrm{~L} / \mathrm{h}$ into the reaction medium at $30{ }^{\circ} \mathrm{C}$, the yield of product was $41 \%$. The yield of OHPMDAP was $55 \%$ at optimum conditions of $[\mathrm{HPMDAP}]_{0}=[\mathrm{KOH}]_{0}=0.05 \mathrm{~mol} / \mathrm{L}$ at $60{ }^{\circ} \mathrm{C}$ for $1 \mathrm{~h}$. Under the same conditions, when reaction temperatures increased between 30 and $60{ }^{\circ} \mathrm{C}$, total yield first increased but than decreased between 70 and $90{ }^{\circ} \mathrm{C}$ (see Table 1). It is seen from Table 1 that, the yields of these reactions are dependent upon temperature, time and initial concentrations of oxidant. $\mathrm{NaOCl}$ oxidant was more active than air for the yield of OHPMDAP under the same conditions.

OHPMDAP is dark brown in powder form and it is completely soluble in organic solvents such as DMF, THF and DMSO. It is insoluble in hexane, benzene, toluene, ethyl acetate, $\mathrm{CH}_{2} \mathrm{Cl}_{2}, \mathrm{CHCl}_{3}, \mathrm{CCl}_{4}$ and acetone. OHPMDAP-Cd, OHPMDAP-Co, OHPMDAP-Cu, OHPMDAP$\mathrm{Fe}, \mathrm{OHPMDAP}-\mathrm{Cr}$, OHPMDAP-Ni, OHPMDAP-Pb and OHPMDAP-Zn oligomer-metal complexes are also insoluble in hexane, benzene, toluene, ethyl acetate, $\mathrm{CH}_{2} \mathrm{Cl}_{2}$, $\mathrm{CHCl}_{3}, \mathrm{CCl}_{4}$ and acetone. These oligomer-metal complexes are partly soluble in DMF. The oxidative polymerization experiments of monomer were performed at varying temperatures and times, using different oxidants such as air and $\mathrm{NaOCl}$ (Scheme 2). These oligomers have good solubility in usual organic solvents such as THF and DMF. However, when reaction temperature is increased to about $70^{\circ} \mathrm{C}$, fractions insoluble in THF were obtained as well. Similarly, when reaction time is increased, compounds with higher molecular weights were obtained. This opens up opportunities for various applications such as electroactive and photoactive materials. In addition, the molecular weights of these oligomers could further be increased by utilizing different oxidation reagents such as $\mathrm{KMnO}_{4}$, etc. Both oligoazomethines and polyazomethines can be easily prepared by oxidative polycondensation without special reaction conditions such as high temperature, use of special catalysts. On the other hand, when obtained by melt polycondensation, a major drawback of azomethine oligomer is its solubility in common organic solvents due to their rigid chain structure.

\subsection{Structure of OHPMDAP}

$M_{n}$ and $M_{w}$ values of OHPMDAP were calculated by using SEC chromatograms, according to a polystyrene standard calibration curve and are given in Table 2. The $M_{n}, M_{w}$ and PDI values of OHPMDAP were found to be 1500 , $2100 \mathrm{~g} \mathrm{~mol}^{-1}$ and 1.400, using NaOCl; 900, $1100 \mathrm{~g} \mathrm{~mol}^{-1}$ and 1.222 , using air, respectively. When reaction temperature and reaction time increased, molecular weight distribution (MWD) of OHPMDAP increased, but the yield of OHPMDAP decreased. Increasing the polymerization time, temperature and oxidant concentration increased the molecular weight and MWD of OHPMDAP.

The UV-vis spectroscopic studies were carried out with DMSO and methanol solutions of the HPMDAP and OHPMDAP. At the spectra of HPMDAP, $\mathrm{K}$ bands of phenol and $=\mathrm{N}-\mathrm{C}_{5} \mathrm{H}_{3} \mathrm{~N}-\mathrm{N}=$ were observed at 225 and $327 \mathrm{~nm}$, respectively. Benzene band of HPMDAP and strength $\mathrm{R}$ band of $=\mathrm{N}-\mathrm{C}_{5} \mathrm{H}_{3} \mathrm{~N}-\mathrm{N}=$ groups were observed at 272 and $335 \mathrm{~nm}$, respectively. $\lambda_{\max }$ values of OHPMDAP were observed at 205, 230, 274 and $368 \mathrm{~nm}$. K and R bands were observed at 230 and $274 \mathrm{~nm}$, respectively, at UV-vis spectra of OHPMDAP. The band of $=\mathrm{N}-$ $\mathrm{C}_{5} \mathrm{H}_{3} \mathrm{~N}-\mathrm{N}=$ group was observed at $368 \mathrm{~nm}$. The UV-vis spectra shows specific bands for $\lambda_{\text {max }}$ indicating aromatic and azomethinic $\pi \rightarrow \pi^{*}$ transitions at about 280 and $350 \mathrm{~nm}$, respectively, [26].

The FT-IR spectral data of HPMDAP, OHPMDAP and OHPMDAP-metal complexes are given in Table 3. Bands of $-\mathrm{OH}$ and $-\mathrm{CH}=\mathrm{N}$ groups were observed at 3290 and 1608; 3341 and $1621 \mathrm{~cm}^{-1}$, respectively, at the FT-IR spectra of HPMDAP and OHPMDAP. Metal-O and Metal-N values of oligomer-metal complexes were observed between $562-590$ and $603-677 \mathrm{~cm}^{-1}$, respectively. In order to identify the structures of monomer and oligomer, the ${ }^{1} \mathrm{H}-\mathrm{NMR}$ spectra were recorded in DMSO- $\mathrm{d}_{6}$. ${ }^{1} \mathrm{H}-\mathrm{NMR}$ and ${ }^{13} \mathrm{C}-\mathrm{NMR}$ spectra of the monomer and oligomer are given in Figs. 1, 2 and 3, respectively. The

Table 2 Number average molecular weight $\left(\mathrm{M}_{\mathrm{n}}\right)$, weight average molecular weight $\left(\mathrm{M}_{\mathrm{w}}\right)$, polydispersity index (PDI) and \% values of oxidative polycondensation products of OHPMDAP

\begin{tabular}{|c|c|c|c|c|c|c|c|c|c|c|c|c|c|c|c|}
\hline \multirow[t]{3}{*}{ Compounds } & \multicolumn{15}{|c|}{ Molecular weight distribution parameters } \\
\hline & \multicolumn{3}{|l|}{ Total } & \multicolumn{4}{|c|}{ Fraction I } & \multicolumn{4}{|c|}{ Fraction II } & \multicolumn{4}{|c|}{ Fraction III } \\
\hline & $\mathrm{M}_{\mathrm{n}}$ & $\mathrm{M}_{\mathrm{w}}$ & PDI & $\mathrm{M}_{\mathrm{n}}$ & $\mathrm{M}_{\mathrm{w}}$ & PDI & $\%$ & $\mathrm{M}_{\mathrm{n}}$ & $\mathrm{M}_{\mathrm{w}}$ & PDI & $\%$ & $\mathrm{M}_{\mathrm{n}}$ & $\mathrm{M}_{\mathrm{w}}$ & PDI & $\%$ \\
\hline OHPMDAP $^{\mathrm{a}}$ & 1500 & 2100 & 1.400 & 1800 & 2700 & 1.500 & 90 & 6600 & 7000 & 1.061 & 5 & 45600 & 67700 & 1.485 & 5 \\
\hline OHPMDAP $^{\mathrm{b}}$ & 900 & 1100 & 1.222 & 1200 & 1400 & 1.167 & 50 & 2600 & 3000 & 1.154 & 45 & 15400 & 16100 & 1.046 & 5 \\
\hline
\end{tabular}

\footnotetext{
${ }^{\text {a }} \mathrm{NaOCl}$ oxidant (Table 1, sample no.: 3)

b Air oxidant (Table 1, sample no.: 16)
} 
Table 3 FT-IR spectral data of HPMDAP, OHPMDAP and oligomer-metal complexes

\begin{tabular}{|c|c|c|c|c|c|c|}
\hline \multirow[t]{2}{*}{ Compounds } & \multicolumn{6}{|c|}{ Wave number $\left(\mathrm{cm}^{-1}\right)$} \\
\hline & $-\mathrm{OH}$ & $-\mathrm{CH}=\mathrm{N}$ & $-\mathrm{C}=\mathrm{C}$ & $-\mathrm{C}-\mathrm{O}$ & Metal-O & Metal-N \\
\hline HPMDAP & 3290 & 1608 & $1573,1554,1486$ & 1273 & - & - \\
\hline OHPMDAP & 3341 & 1621 & 1563 & 1280 & - & - \\
\hline OHPMDAP-Cu & 3466 & 1611 & $1565,1520,1446$ & 1274 & 562 & 637 \\
\hline OHPMDAP-Ni & 3447 & 1602 & $1560,1520,1463$ & 1194 & 568 & 632 \\
\hline OHPMDAP-Co & 3344 & 1606 & $1561,1521,1443$ & 1192 & 564 & 636 \\
\hline OHPMDAP-Fe & 3362 & 1620 & 1514,1451 & 1196 & 562 & 603 \\
\hline OHPMDAP-Pb & 3402 & 1604 & $1562,1529,1467$ & 1280 & 572 & 668 \\
\hline OHPMDAP-Zn & 3197 & 1608 & $1565,1529,1472$ & 1178 & 570 & 677 \\
\hline OHPMDAP-Cr & 3365 & 1606 & $1557,1490,1465$ & 1274 & 568 & 641 \\
\hline OHPMDAP-Cd & 3309 & 1603 & $1562,1532,1457$ & 1279 & 579 & 668 \\
\hline
\end{tabular}

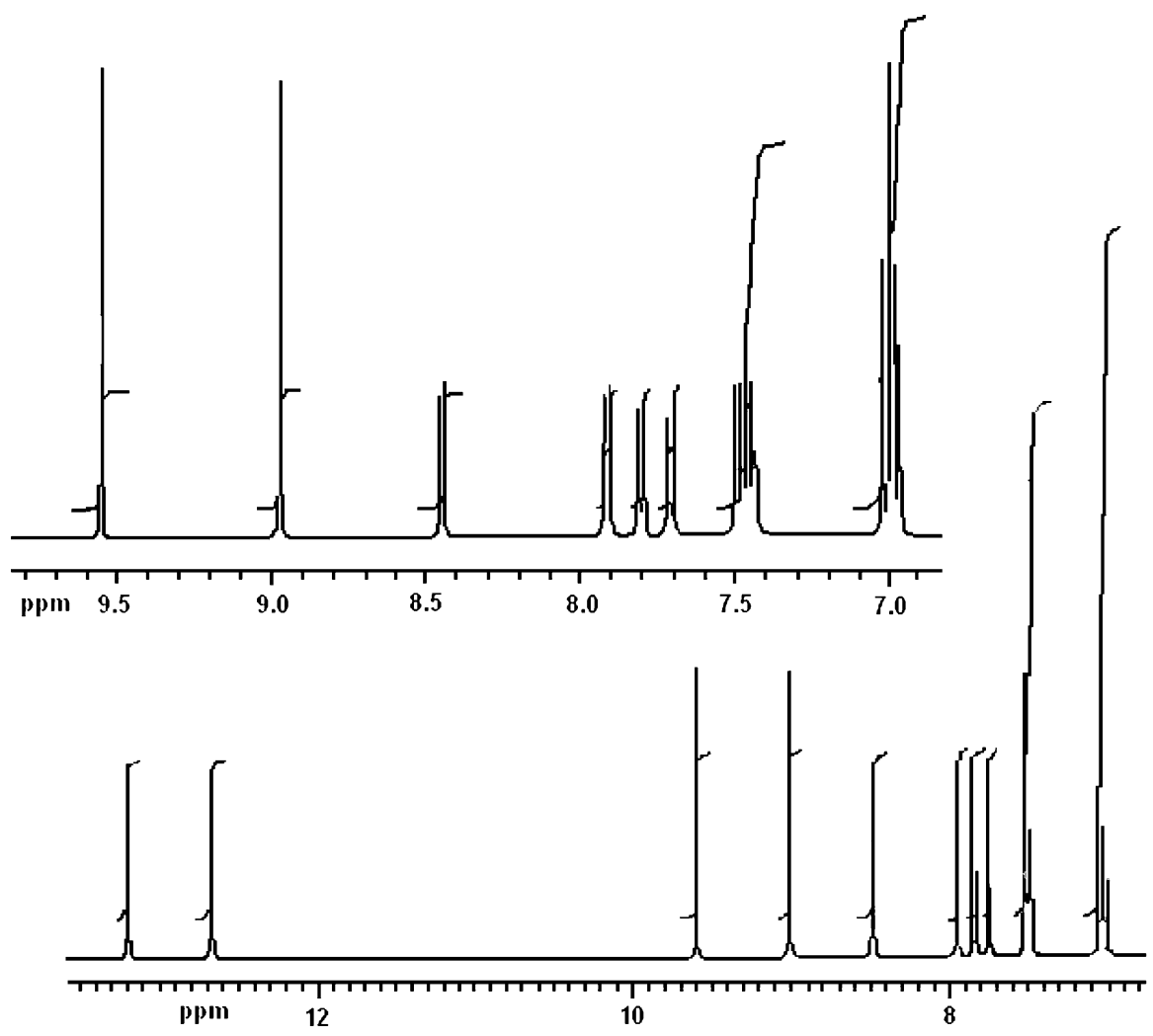

Fig. $1{ }^{1} \mathrm{H}-\mathrm{NMR}$ spectrum of 2,3-bis[(2-hydroxyphenyl)methylene $]$ diaminopyridine

signals of phenyl $-\mathrm{OH}$, and $-\mathrm{CH}=\mathrm{N}$ groups were observed at $13.17,12.64$ and 9.57, $8.99 \mathrm{ppm}$ and 13.18, 12.60 and 9.56, $8.98 \mathrm{ppm}$, respectively, at the ${ }^{1} \mathrm{H}-\mathrm{NMR}$ spectra of HPMDAP and OHPMDAP. The FT-IR spectral data and the results of the ${ }^{1} \mathrm{H}-{ }^{13} \mathrm{C}-\mathrm{NMR}$ spectra of the OHPMDAP confirm each other. Other phenol derivatives were also polymerized, and the results were reported in the literature [16].

Cross-linking in polymer structure is expected in cases where ortho and para positions in the corresponding monomer structure are unsubstituted. ${ }^{13} \mathrm{C}-\mathrm{NMR}$ studies on OHPMDAP indicate that the linkage between any two adjacent phenyl rings is mostly at ortho and para positions (Figs. 2 and 3). The peak values for C1, C7, C13 and C19 observed at $161.63,166.06,164.67$ and $160.79 \mathrm{ppm}$ in the monomer and at 161.64, 166.01, 164.65 and $160.80 \mathrm{ppm}$ in the oligomer, respectively. According to ${ }^{1} \mathrm{H}-\mathrm{NMR}$, proton integral value of hydroxyl group was found to be 1.000 . Thus the phenyl rings in the oligomer appears to be linked primarily at ortho and para positions. On the other hand, a 


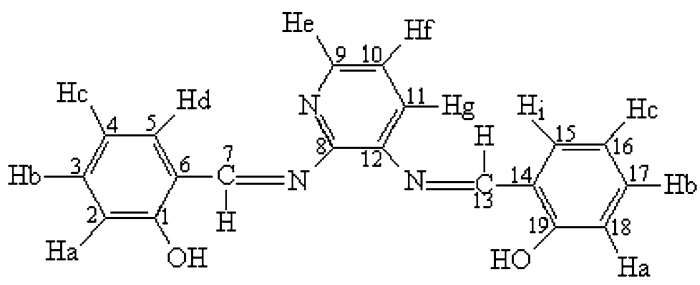

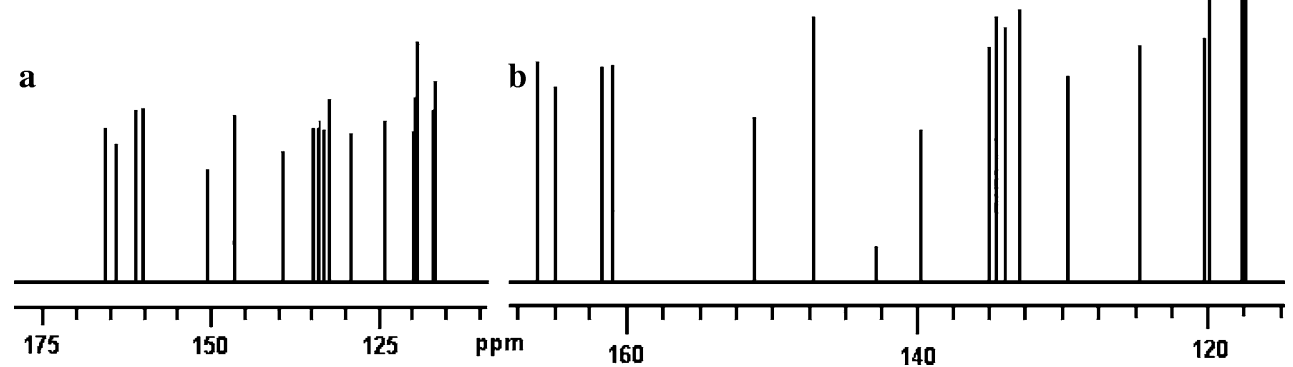

Fig. $2{ }^{13} \mathrm{C}$-NMR spectra of 2,3-bis[(2-hydroxyphenyl)methylene]diaminopyridine (a) and oligo-2,3-bis[(2-hydroxyphenyl)methylene]diaminopyridine (b)

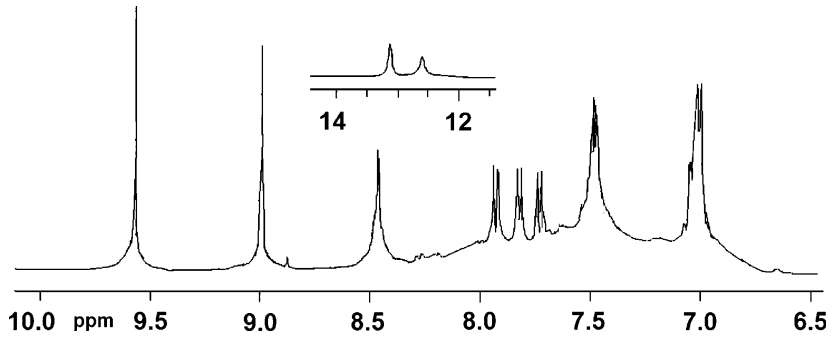

Fig. $3{ }^{1} \mathrm{H}-\mathrm{NMR}$ spectrum of oligo-2,3-bis[(2-hydroxyphenyl) methylene]diaminopyridine

new peak in $143.05 \mathrm{ppm}$ was observed at the ${ }^{13} \mathrm{C}-\mathrm{NMR}$ spectra of the oligomer. This peak is not present in the case of monomer. This new peak at the spectra of oligomer has assigned to $\mathrm{C}-\mathrm{C}$ coupling system (Scheme 2).

\subsection{Thermal Studies}

Thermal degradations of HPMDAP, OHPMDAP, OHPMDAP-Cd, OHPMDAP-Co, OHPMDAP-Cu, OHPMDAP$\mathrm{Fe}$, OHPMDAP-Cr, OHPMDAP-Ni, OHPMDAP-Pb and OHPMDAP-Zn were studied by TGA-DTGA-DTA analyses under $\mathrm{N}_{2}$ medium, and thermal analyses results and the curves of these analyses are given in Table 4 and Fig. 4 (TG curves), respectively. The initial degradation temperature of OHPMDAP was found to be higher than HPMDAP. The initial degradation temperature of HPMDAP and OHPMDAP were found as 201 and $233{ }^{\circ} \mathrm{C}$, respectively. The oligomer formed carbines residue at high amount such as $29.36 \%$ at $1000{ }^{\circ} \mathrm{C}$. Due to long conjugated band systems, oligomer showed higher resistance

Table 4 Thermal decomposition values of HPMDAP, OHPMDAP and oligomer-metal complexes

\begin{tabular}{|c|c|c|c|c|c|c|c|}
\hline \multirow[t]{2}{*}{ Compounds } & \multicolumn{5}{|l|}{ TGA } & \multicolumn{2}{|l|}{ DTA } \\
\hline & ${ }^{\mathrm{a}} \mathrm{T}_{\text {on }}$ & ${ }^{\mathrm{b}} \mathrm{T}_{\max }$ & ${ }^{\mathrm{c}} \mathrm{T}_{20}\left({ }^{\circ} \mathrm{C}\right)$ & ${ }^{\mathrm{d}} \mathrm{T}_{50}\left({ }^{\circ} \mathrm{C}\right)$ & Residue at $1000{ }^{\circ} \mathrm{C}(\%)$ & Exo & Endo \\
\hline HPMDAP & 201 & 224,315 & 295 & 462 & 34.94 & 219 & 150 \\
\hline OHPMDAP & 233 & 311 & 301 & 416 & 29.36 & 197 & 146 \\
\hline OHPMDAP-Co & 202 & $255,518,642,886$ & 500 & 930 & 47.80 & 653 & - \\
\hline OHPMDAP-Ni & 209 & 250,393 & 363 & 716 & 40.66 & - & - \\
\hline OHPMDAP-Cd & 162 & $191,377,630,895$ & 399 & 739 & 30.00 & - & - \\
\hline OHPMDAP-Zn & 287 & $355,724,851$ & 646 & 859 & 38.13 & - & - \\
\hline OHPMDAP-Cr & 233 & 288 & 280 & 358 & 27.17 & - & - \\
\hline OHPMDAP-Cu & 261 & 330,670 & 323 & 867 & 45.27 & 232 & - \\
\hline OHPMDAP-Pb & 285 & 285,583 & 587 & 879 & 36.99 & - & 415 \\
\hline OHPMDAP-Fe & 485 & 234,517 & 510 & - & 63.72 & 115,524 & - \\
\hline
\end{tabular}

\footnotetext{
a The onset temperature

b Temperature of the maxima of the peak

c Temperature corresponding to $20 \%$ weight loss

d Temperature corresponding to $50 \%$ weight loss
} 
Fig. 4 TGA curves of monomer, oligomer and oligomer-metal complexes

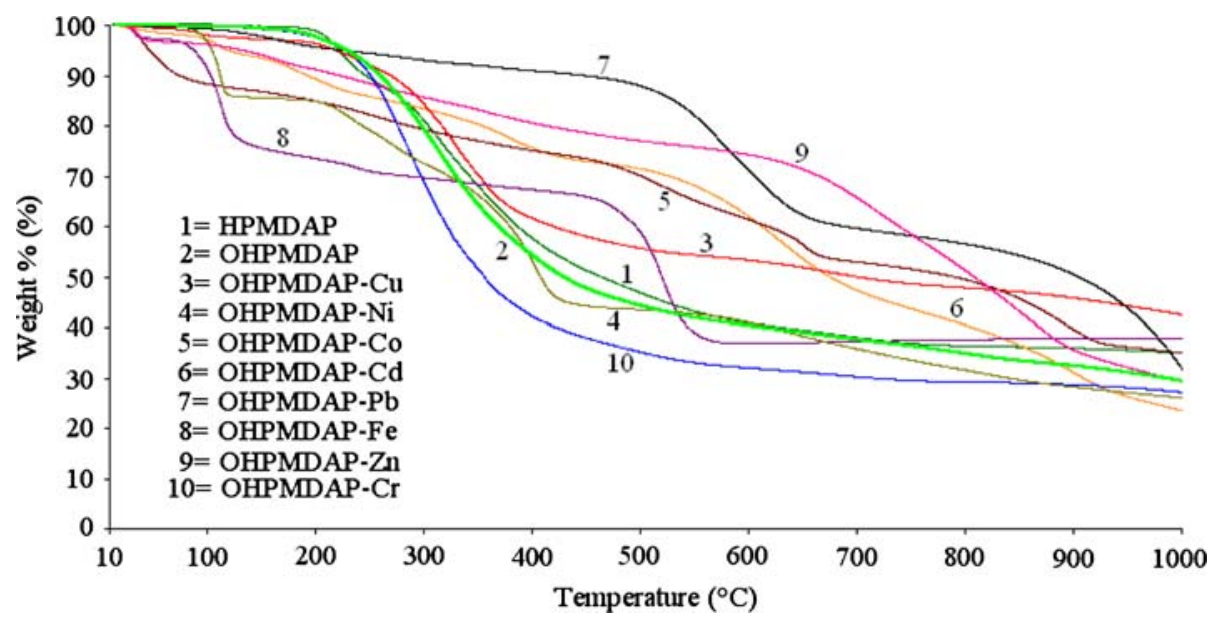

against high temperatures compared to monomer. The high thermal stability of OHPMDAP demonstrated the formation of $\mathrm{C}-\mathrm{C}$ coupling system. OHPMDAP-Fe showed higher thermal stability compared to other oligomer-metal complex compounds. The initial degradation temperature was found to be $485{ }^{\circ} \mathrm{C}$ and $63.72 \%$ weight loss was observed at $1000{ }^{\circ} \mathrm{C}$, for OHPMDAP-Fe. According to TGA curves, the high thermal stability of oligomer-metal complexes may indicate the formation of metal-oxygen valance and metal-nitrogen coordination bonds between oligomer-metal ions. The weight losses seen between 3 and $25 \%$ in TGA and DTGA curves of oligomer-metal complexes (Fig. 4) in the temperature range of $50-200{ }^{\circ} \mathrm{C}$ which correspond to the loss of crystallization water (50$150{ }^{\circ} \mathrm{C}$ ) and coordination water $\left(150-200{ }^{\circ} \mathrm{C}\right)$ indicate the presence of water. This also explains the differences appeared between the elemental analysis values experimentally found and calculated. OHPMDAP-Cr showed lower thermal stability against thermal degradation than other oligomer-metal complexes. According to TG analyses, weight loses of oligomer metal complexes changed at $1000{ }^{\circ} \mathrm{C}$ as follows: OHPMDAP-Fe $>$ OHPMDAP-Co $>$ OHPMDAP-Cu $>$ OHPMDAP-Ni $>$ OHPMDAP-Zn $>$ OHPMDAP-Pb $>$ OHPMDAP-Cd $>$ OHPMDAP-Cr. It is obvious that, OHPMDAP-Fe complex showed higher thermal stability than other complexes. This can be discussed in terms of repulsion among electron pairs in the valence shell of the central ion.

\subsection{Electrical Properties}

HPMDAP and OHPMDAP have conductivities of $1.44 \times 10^{-12}$ and $2.49 \times 10^{-12} \mathrm{~S} / \mathrm{cm}$, respectively. Their conductivities could be increased by about three orders of magnitude (up to $10^{-3} \mathrm{~S} / \mathrm{cm}$ ) by doping with iodine. Figure 5 shows the results for HPMDAP, OHPMDAP and oligomer-metal complexes doped with iodine for various
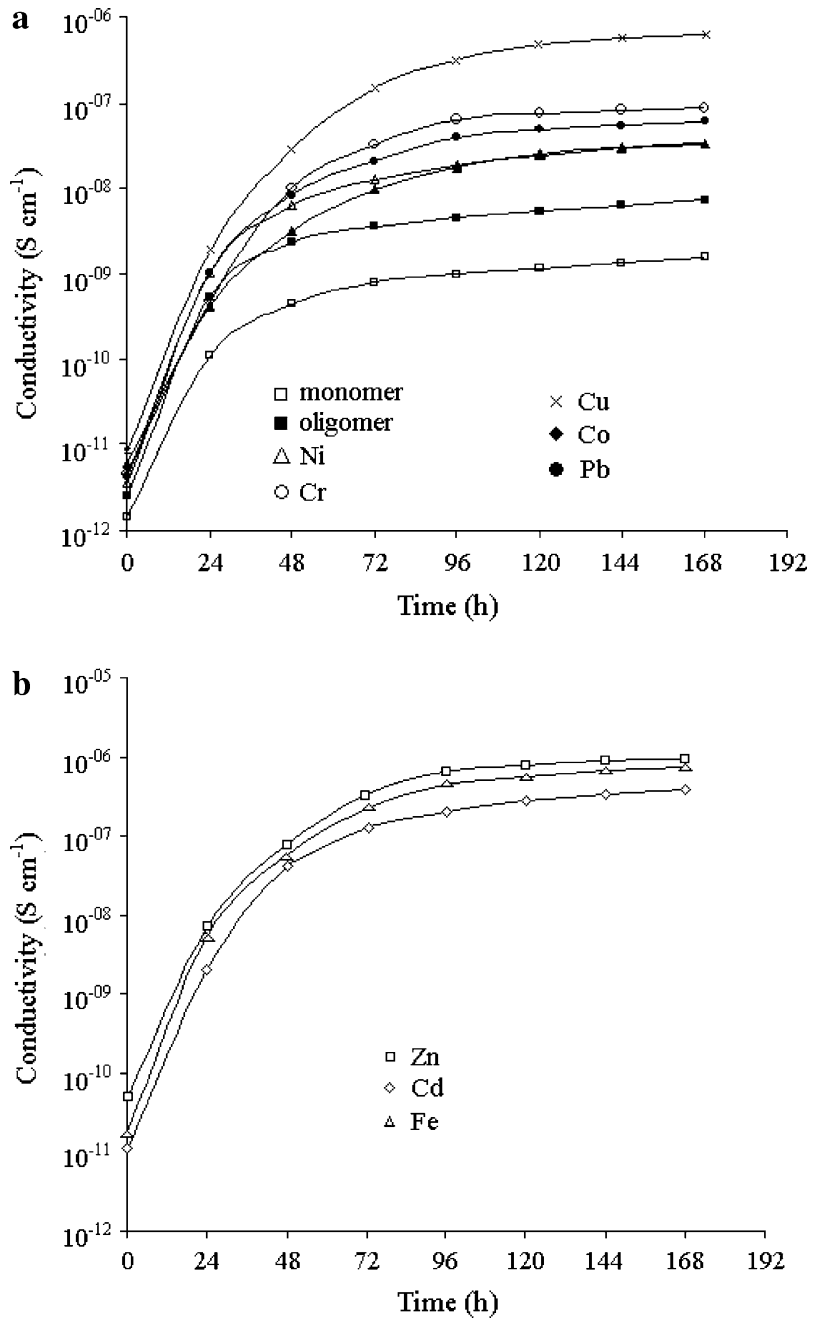

Fig. 5 Changes in electrical conductivities of $\mathrm{I}_{2}$-doped a monomer, oligomer and oligomer-metal complexes $(\mathrm{Ni}, \mathrm{Cu}, \mathrm{Co}, \mathrm{Cr}$ and $\mathrm{Pb}$ ), b $(\mathrm{Zn}, \mathrm{Cd}$ and $\mathrm{Fe})$ versus doping time at $25{ }^{\circ} \mathrm{C}$

times at $25{ }^{\circ} \mathrm{C}$. In the doping of HPMDAP and OHPMDAP with iodine, it was found that the conductivities of HPMDAP and OHPMDAP first increased greatly with doping 


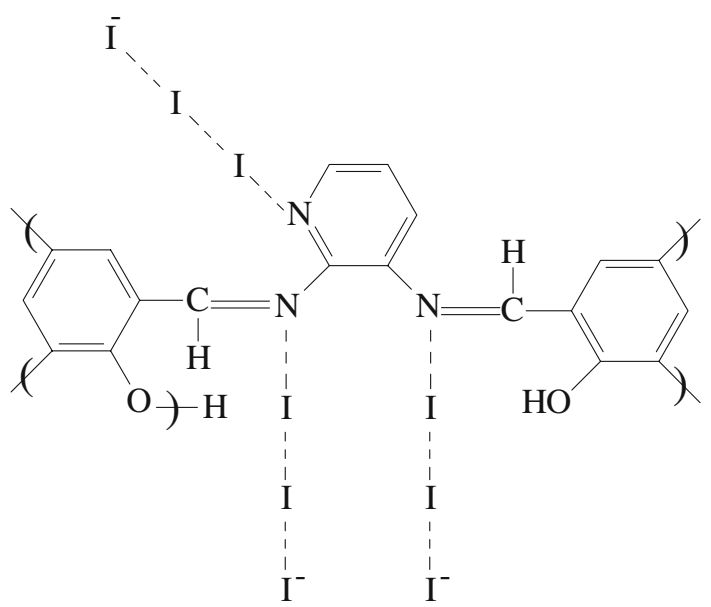

Scheme 3 The nitrogen atom coordination of iodine with Schiff base oligomers

time, but then tended to level-off. The maximal (or saturated) conductivity was determined as $1.54 \times 10^{-9}$ and $7.30 \times 10^{-9} \mathrm{~S} / \mathrm{cm}$, respectively. The increase in conductivity could indicate that a charge-transfer complex between compounds and dopant iodine is continuously formed. In order to exclude the influence of doping conditions, the conductivity of doped oligomer metal complexes have been related with the extent of doping. The maximal (or saturated) conductivity values of OHPMDAP$\mathrm{Cu}$, OHPMDAP-Co, OHPMDAP-Cd, OHPMDAP-Zn, OHPMDAP-Pb, OHPMDAP-Ni, OHPMDAP-Fe, OHPM$\mathrm{DAP}-\mathrm{Cr}$, were found to be $6.22 \times 10^{-8}, 6.03 \times 10^{-8}$, $4.02 \times 10^{-7}, 9.41 \times 10^{-7}, 3.41 \times 10^{-8}, 3.23 \times 10^{-8}$, $7.51 \times 10^{-7}$ and $8.75 \times 10^{-8} \mathrm{~S} / \mathrm{cm}$, respectively, (see Fig. 5). According to the values obtained, the highest conductivity was observed for OHPMDAP-Zn compound. Diaz et al. [25]. had been suggested the conductivity mechanisms of Schiff base polymers for doping with iodine. Nitrogen is a very electronegative element and it is capable of coordinating an iodine molecule. Coordination of iodine during doping of OHPMDAP is as follows (Scheme 3). Coordination of iodine with Schiff base polymers and pyridine solutions on nitrogen atom [27, 28].

As seen from these results, the conductivity of the oligomer is higher than that of the monomer. This may be ascribed to the conjugation length in the complexes arising from delocalization of $\pi$-electrons in the chelate ring. The increasing conjugation length in the complexes may lead to higher conductivity [29-31]. In the case of the doped
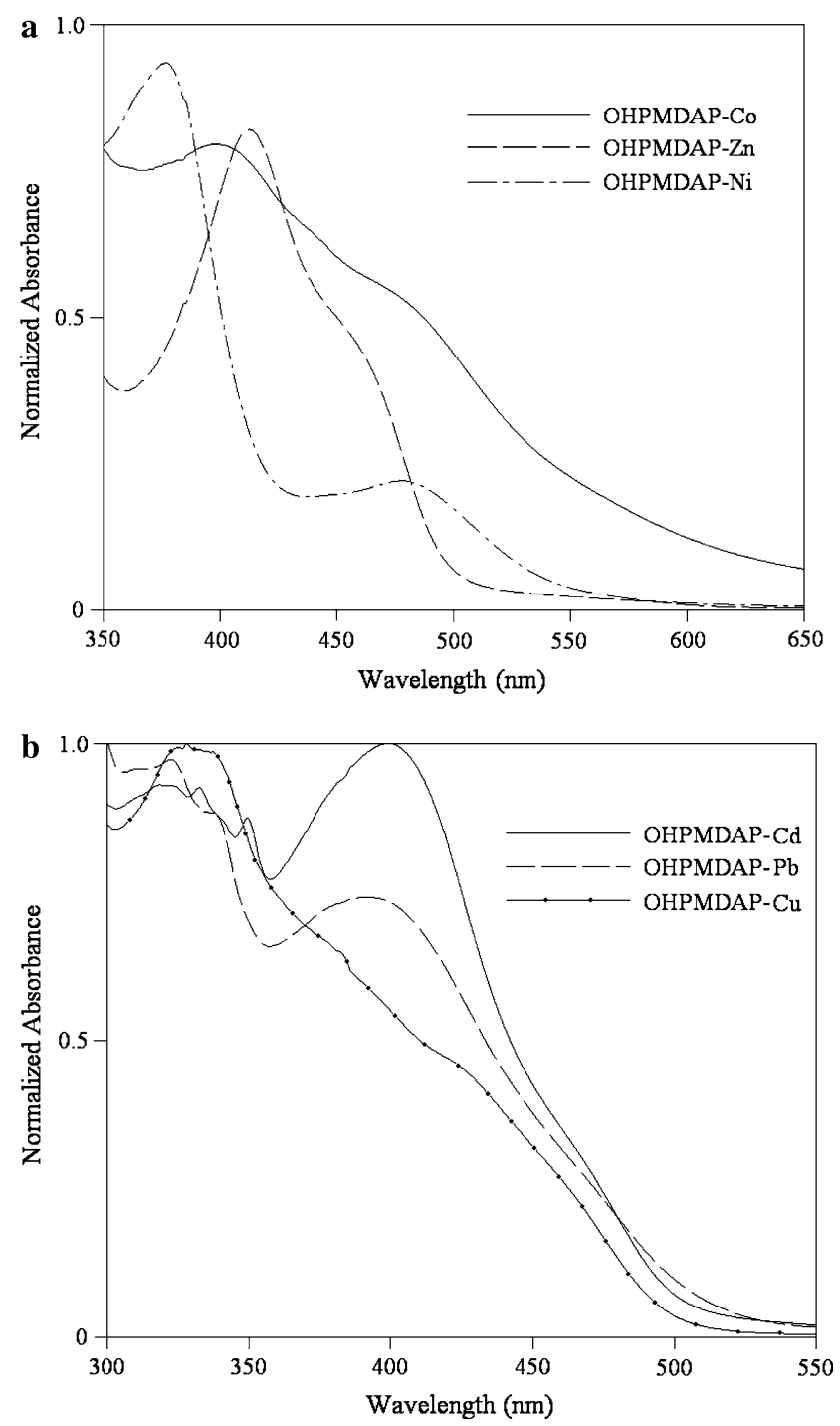

Fig. 6 Absorption spectra of selected oligomer-metal complexes a OHPMDAP-Co, OHPMDAP-Zn and OHPMDAP-Ni b OHPMDAP-Cd, OHPMDAP-Pb and OHPMDAP-Cu

oligomer-metal complexes, if one ignores the little details, the behaviors of the nine oligomer-metal complexes are clearly similar. The curves are mostly indistinguishable. It can be noticed that, the introduction of the metal ions into organic oligomer increased its electrical conductivity.

The optical band gaps $\left(E_{g}\right)$ of monomer, oligomer and its oligomer-metal complex compounds were calculated from their absorption edges. The absorption spectra and data of monomer, oligomer and oligomer-metal complexes are given in Table 5 and Fig. 6 . The optical band gap $\left(E_{g}\right)$

Table 5 Optical band gaps $\left(E_{g}\right)$ and $\lambda_{\max }(\mathrm{nm})$ values of monomer, oligomer and oligomer-metal complexes

\begin{tabular}{lllllllll}
\hline & HPMDAP & OHPMDAP & OHPMDAP-Cu & OHPMDAP-Ni & OHPMDAP-Co & OHPMDAP-Pb & OHPMDAP-Zn & OHPMDAP-Cd \\
\hline$\lambda_{\text {Max }}$ & 336 & 368 & 328 & 478 & 398 & 391 & 412 & 399 \\
$E_{\mathrm{g}}$ & 2.90 & 2.76 & 2.49 & 2.28 & 2.22 & 2.43 & 2.49 & 2.47 \\
\hline
\end{tabular}


Table 6 Elemental analyses data and yields of HPMDAP, OHPMDAP and oligomer-metal complexes

\begin{tabular}{lllllll}
\hline Calculated (experimentally found, $\%)$ & & & \\
\hline Compounds & $\mathrm{C}$ & $\mathrm{H}$ & $\mathrm{N}$ & Metal & $\mu_{\text {eff }}$ & Yield of compounds $(\%)$ \\
\hline HPMDAP & $71.91(71.80)$ & $4.76(4.68)$ & $13.24(13.15)$ & - & - & 78 \\
OHPMDAP & $72.84(72.69)$ & $3.54(4.00)$ & $13.41(13.17)$ & - & - & 69 \\
OHPMDAP-Cu & $60.87(59.44)$ & $2.40(2.71)$ & $11.21(10.75)$ & $16.97(15.14)$ & 2.00 & 58 \\
OHPMDAP-Ni & $61.67(54.98)$ & $2.43(3.38)$ & $11.36(10.13)$ & $15.88(11.75)$ & Diamag. & 44 \\
OHPMDAP-Co & $61.63(54.95)$ & $2.43(3.37)$ & $11.35(10.12)$ & $15.93(14.50)$ & Diamag. & 39 \\
OHPMDAP-Pb & $44.00(43.25)$ & $1.74(1.90)$ & $8.11(7.97)$ & $39.98(30.35)$ & Diamag. & 37 \\
OHPMDAP-Cd & $53.85(49.63)$ & $2.13(2.83)$ & $9.92(9.14)$ & $26.55(16.65)$ & Diamag. & 46 \\
OHPMDAP-Fe & $62.15(51.94)$ & $2.45(4.10)$ & $11.45(9.57)$ & $15.22(14.20)$ & 5.91 & 61 \\
OHPMDAP-Zn & $60.58(57.81)$ & $2.39(2.79)$ & $11.16(10.65)$ & $17.37(15.58)$ & Diamag. & 40 \\
OHPMDAP-Cr & $62.81(61.95)$ & $2.48(2.58)$ & $11.57(10.78)$ & $14.32(10.25)$ & Diamag. & 35
\end{tabular}

values of HPMDAP, OHPMDAP, OHPMDAP-Co, OHPMDAP-Cu, OHPMDAP-Ni, OHPMDAP-Zn, OHPMDAP$\mathrm{Pb}$ and OHPMDAP-Cd were found to be 2.90, 2.75, 2.22, $2.49,2.28,2.49,2.43$ and $2.47 \mathrm{eV}$, respectively. According to these values, $E_{g}$ value of OHPMDAP-Co was lower than those of the other oligomer-metal complexes.

\subsection{Geometrical Structures of Metal Complexes}

The geometrical structures of the above mentioned metal chelates were determined by their magnetic spectra. The elemental analyses were satisfactory and showed that the complexes have a ligand-to-metal ratio of $2: 1$. The results of elemental analysis are given Table 6. Most of the band shifts observed at wave number region of $1180-905 \mathrm{~cm}^{-1}$ at FT-IR spectra are in agreement with the structural changes observed in the molecular carbon skeleton after complexation, which cause some important changes in $(\mathrm{C}-\mathrm{C})$ bond lengths. The $v(\mathrm{M}-\mathrm{N})$ band for ligand complexes are appeared in the wave number range of 603$677 \mathrm{~cm}^{-1}$. New peaks which have sharp, small or broad intensities observed in the wave number range of 562$579 \mathrm{~cm}^{-1}$ are assigned to $\mathrm{M}-\mathrm{O}$ vibration. The magnetic moment of the iron complex is $5.91 \mathrm{BM}$ which is close to the spin only value indicating an octahedral structure for the complex [32]. According to the magnetic susceptibility measurement of copper complex, this value is $2.00 \mathrm{BM}$ which is indicative of the appearance of the copper complex in a square planar geometry [33]. $\mathrm{Ni}^{+2}, \mathrm{Co}^{+2}, \mathrm{~Pb}^{+2}$, $\mathrm{Cd}^{+2}, \mathrm{Zn}^{+2}$ and $\mathrm{Cr}^{+3}$ complexes are diamagnetic. The diamagnetic nature coupled with elemental analysis data suggests a tetrahedral environment of chelating ligands around the metal ions [34]. $\mathrm{Ni}^{+2}$ complex is diamagnetic and has possibly a square planar geometry.

\section{Conclusion}

Oligo-2,3-bis[(2-hydroxyphenyl)methylene]diaminopyridine was synthesized by oxidants of $\mathrm{NaOCl}$ and air in an aqueous alkaline medium. The yield of OHPMDAP was found to be $69 \%$ for $\mathrm{NaOCl}$ oxidant. The $M_{n}, M_{w}$ and PDI values of OHPMDAP were found to be $900,1100 \mathrm{~g} \mathrm{~mol}^{-1}$, and 1.222, respectively, using air oxidant and 1500, $2100 \mathrm{~g} \mathrm{~mol}^{-1}$ and 1.400 , respectively, using $\mathrm{NaOCl}$ oxidant. In the oxidative polycondensation reaction of HPMDAP, air showed less activity than $\mathrm{NaOCl}$ oxidant The ${ }^{1} \mathrm{H}$ and ${ }^{13} \mathrm{C}$-NMR spectral analyses demonstrated that, the formation of oligomers from oxidative polycondensation of HPMDAP proceeds over ortho and para carbons of phenyl rings. The results of TG-DTA analyses showed that, OHPMDAP have enough resistance against thermal degradation. The results of this study showed that aromatic oligoazomethine and its metal complexes were interesting members of conjugated compounds whose electronic structure and properties can be regulated over a wide range by varying complexation. This opens up opportunities for various applications such as electroactive and organic electroluminescent devices (OELD).

Open Access This article is distributed under the terms of the Creative Commons Attribution Noncommercial License which permits any noncommercial use, distribution, and reproduction in any medium, provided the original author(s) and source are credited.

\section{References}

1. R.C. Liang, A.R. Pokora and W.L. Cyrus Jr., U.S. Patent 5, (1993), 212044

2. F. Bruno, J.A. Akkara, L.A. Samuelson, D.L. Kaplan, B.K. Mandal, K.A. Marx, J. Kumar, S.K. Tripathy, Langmuir 11, 889-892 (1995) 
3. P.W. Kopf. Encyclopedia of Polymer Science and Engineering, vol. 11 (Wiley, New York, 1985)

4. M.S. Ayyagari, K.A. Marx, S.K. Tripathy, J.A. Akkara, D.L. Kaplan, Macromolecules 28, 5192-5197 (1995)

5. İ. Kaya, A. Bilici, J. Macromol. Sci. A: Pure Appl. Chem. 43 (4-5), 719-733 (2006)

6. P. Kovacic, A. And Kyriakis, Tetrahedron Lett. 11, 467-469 (1962)

7. D. Kumar, D.C. Sharma, Eur. Polym. J. 37(8), 1053-1060 (1998)

8. B.A. Mamedov, Y.A. Vidadi, D.N. Alieva, A.V. Ragimov, Polym. Int. 43(2), 126-128 (1997)

9. M.E. Mansour, A.A. Kassem, H. Nour and A. Toukhy, Macromolecular Reports, 1991, pp. 103-109

10. C.S. Marvel, N. Tarkoy, J. Am. Chem. Soc. 80, 832-838 (1958)

11. V.T. Kasumov, Spectrochim. Acta A 57, 451-460 (2001)

12. R. Antony, G.L. Tembe, M. Ravindranathan, R.N. Ram, Polymer 18, 4327-4333 (1998)

13. N. Chantarassiri, T. Tuntulani, P. Tongroung, R. Seangprasertkit, W. Wannarong, Eur. Polym. J. 36, 695-702 (2000)

14. X. Li, C. Li, S. Li, Synth. Met. 60, 285-288 (1993)

15. S. Kobayashi, H. Higashimura, Prog. Polym. Sci. 28(6), 10151048 (2003)

16. S.C. Suh, S.C. Shim, Synth. Met. 114(1), 91-95 (2000)

17. A.V. Ragimov, B.A. Mamedov, S.G. Gasanova, Polym. Int. 43(4), 343-346 (1997)

18. A.V. Ragimov, B.A. Mamedov, Sh.I. Mustafaeva, Polymer 30(10), 1851-1855 (1989)

19. J.C. Pessoa, I. Correia, Inorganica Chim. Acta 293, 1-11 (1999)
20. İ. Kaya, S. Çulhaoğlu, M. Gül, Synth. Met. 156(16-17), 11231132 (2006)

21. İ. Kaya, H.O. Demir, A.R. Vilayetoğlu, Synth. Met. 126(2-3), 183$191(2002)$

22. H. Mart, A.R. Vilayetoğlu, Polym. Degrad. Stab. 83(2), 255-258 (2004)

23. A.R. Fakhari, A.R. Khorrami, H. Naeimi, Talanta 66(4), 813-817 (2005)

24. İ. Kaya, N. Cihangiroğlu, J. Polym. Res. 11(1), 37-42 (2004)

25. F.R. Diaz, J. Moreno, L.H. Tagle, G.A. East, D. Radic, Synth. Met. 100(2), 187-193 (1999)

26. M. Cazacu, M. Marcu, A. Vlad, G.I. Rusu, M. Avadanei, J. Organomet. Chem. 689, 3005-3011 (2004)

27. H. Sakai, T. Matsuyama, Y. Meada, H. Yamoka, J. Chem. Phys. 75, 5155-5159 (1981)

28. N. Satoh, T. Nakashima, K. Yamamoto, J. Am. Chem. Soc. 127, 13030-13038 (2005)

29. N. Sarı, P.Z. Gürkan, Naturforsch 59b(6), 692-698 (2004)

30. N. Sar1, J. Macromol. Sci. A: Pure Appl. Chem. 43, 1609-1618 (2006)

31. A. El-Shekeil, M. Al-Khader, A.O. Abu-Bakr, J. Macromol. Sci. A: Pure Appl. Chem. 41(11), 501-522 (2004)

32. Z.H. Abd El-Wahab, M.R. El-Sarrag, Spectrochim. Acta A 60, 271-277 (2004)

33. G.G. Mohamed, Z.H. Abd El-Wahab, J. Therm. Anal. Calorim. 73, 347-359 (2003)

34. T. Kaliyappan, A. Raman, P. Kannan, J. Macromol. Sci. A: Pure Appl. Chem. 36(4), 517-530 (1999) 